\title{
The Roles of Authenticity and Immediacy in Engaging Family Historians in Online Learning Designed to Advance Academic Skills
}

\author{
${ }^{1}$ History \& Classics, School of Humanities, University of Tasmania, Hobart TAS 7005, Australia, E-mail: \\ Kristyn.Harman@utas.edu.au
}

\begin{abstract}
:
A rapid increase in the availability of digitized archival resources of relevance to family historians together with increasing individual fascination with genealogical research led to the University of Tasmania introducing a fully online Diploma of Family History in 2016. The course's emphasis on authenticity through a variety of modalities and the sense of immediacy with which its online learning environment is imbued combine to engage and retain students' interest as they focus on locating and contextualizing their own ancestors as research subjects. Permeating family history with academic skills promotes best practice in locating, analyzing, storing, and publicly presenting family-centric research materials for the edification of current and future generations.
\end{abstract} Keywords: family history, authenticity, immediacy, online learning and teaching, academic skills DOI: 10.1515/iph-2019-0018

As an impressionable child holidaying in New Zealand's South Island I was treated to a visceral experience as we communed with our family's past. This feeling emanated from a visit to a wooden home in Kaikoura where a deep silence was punctuated only by the rhythmic ticking of numerous old clocks. The seconds marked time's inevitable march as an elderly woman tended to her even more elderly mother. At the time of our visit, the older of the two women was tiny and frail. Several years past her centenary, she was ensconced in voluminous bedclothes and wore a cloth cap. This diminutive woman, my great-great-aunty Rose Adair, was born Rose Mary Ann Bassett in Sussex, England, in 1870. She still remembered how, as a four-year-old on the long sea voyage out to the colony on the clipper Carnatic, she had lost her bonnet overboard. Young Rose had watched it bob away in the ship's wake.

One of many such vessels laden with hopeful pioneers, the Carnatic was chartered by the New Zealand Shipping Company. The clipper departed London on September 28, 1874 and arrived at Picton January 10, 1874 , then Wellington on January 16, 1875. Being in the living presence of one of New Zealand's last surviving settlers was a compelling experience, one of several that ignited my deep fascination with history, including family history.

Several decades later, following a corporate career and a change in country of residence, I entered the academy. In 2016, my passions for writing, history, learning and teaching, and research culminated in my being appointed as the inaugural course co-ordinator for the University of Tasmania's Diploma of Family History for a three-year term. Our diploma is an interdisciplinary course comprising ten units (from which students select eight) and is available to Australian domestic students. Its key aims are to ensure that family historians develop academic skills in analyzing, synthesizing, storing, managing, and communicating their research within and beyond their family contexts. Skills development emphasizes both technical competence and creative outputs to promote the sharing of knowledge through a range of modalities.

One of the key opportunities involved in coordinating the Diploma of Family History is that it is offered solely online. This has facilitated our providing students with unfettered access to billions of relevant online family history records and the skills to utilize them. In fact, one of the attractions to students in studying with us is full access to Ancestry Library. ${ }^{1}$ We guide students through the processes involved in locating, reading, evaluating, and contextualizing digitized archival records accessed through this database. In doing so, we aim to bridge the gap between family history and academic history through imbuing the former practice with the academic skill set usually associated with the latter. 


\section{Authenticity}

Family historians are motivated by a range of factors with most enjoying "the detective work required to solve family mysteries revealed by secrets, lies and gaps in the record. ${ }^{2}$ With their overwhelming interest in endeavoring to reconstruct their family's past in as accurate a manner as possible, ensuring that people's ancestors were central and their learning experiences were as relevant to the real world as possible was paramount in developing the Diploma of Family History.

Fortunately, online delivery created ample opportunities for us to design, develop, and deliver authentic learning experiences. As I discuss below, key traits of our diploma are that it is place-based, incorporates and fosters engagement in learning activities with real world outcomes, and is research led. Our online learning environment also creates a sense of immediacy and community built using digital tools that invite human interaction. $^{3}$

Reflecting on my approaches to leading the Diploma of Family History, it has become obvious to me how they were shaped by the characteristics of the informal and formal learning experiences that left the deepest impressions on my younger self. This is consistent with Stephen Brookfield's explanation about how "our actions as teachers are based on assumptions we have about how best to help students learn." 4 My early learning experiences, including our family visit to my great-great-aunty Rose, were characterized by strong senses of immediacy and authenticity, qualities that have informed, and continue to inform, my approaches to learning and teaching. Instructor immediacy and authenticity has been recognized as vitally important to teaching online in the digital age. ${ }^{5}$ My conceptualization of these extend well beyond what the lecturer does online to motivate and support learning.

Across the Diploma of Family History, authenticity is articulated and produced through our deep engagement with historic places, people, and archival materials and culminates in students' production of real-world artefacts (such as, for example, written biographies, photo essays, object biographies) as assessment pieces rather than in more traditional argumentative essays. Their own ancestors are central to their learning process. Immediacy is fostered through real-time formative assessment tasks that provide instant feedback to students as they attempt them, as well as interactions with other participants in the course, including student peers, the teaching teams, and invited experts external to the university.

A strength across the Diploma of Family History teaching team is the way in which our academics teach from their areas of research expertise, melding these with family history. To provide an example from history, one of my areas of research is the transportation of Indigenous convicts from across the British Empire to and within the Australian colonies. To deepen students' comprehension of the diversity of convict experience, I drew on this research to create a multimedia learning experience within our Convict Ancestors unit. My overview video lecture on Indigenous Convicts was supplemented by other materials including another video lecture in which I focus what a close reading of an archival document can reveal. A piece of artifice that amplifies the authenticity of the warrant that accompanied Khoisan convict Booy Piet to Van Diemen's Land (now Tasmania) was our incorporation of a voice-over by Basil Sansom reading the words inscribed on it by Chief Justice John Wylde.

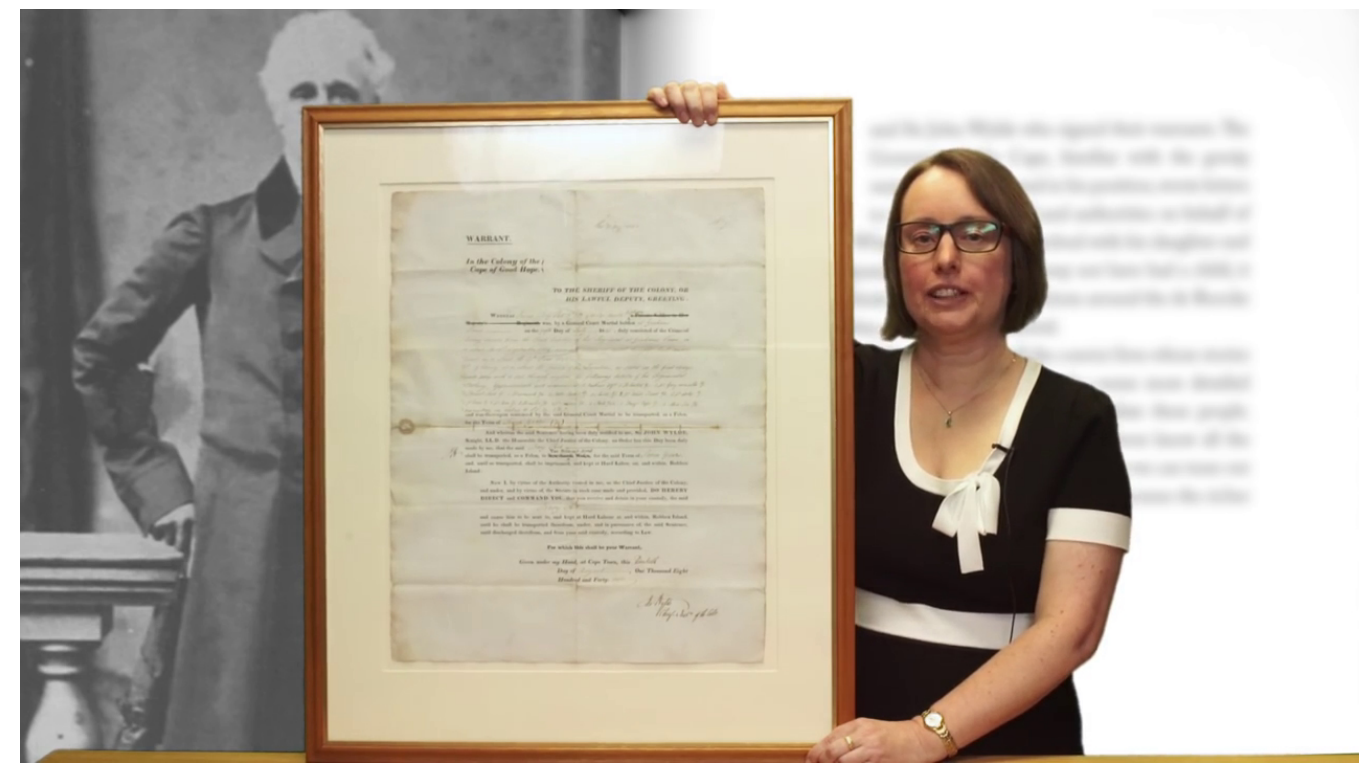

Video 1: Video about Indigenous Convicts from the Convict Ancestors unit featuring Associate Professsor Kristyn Harman 
One of the particular challenges of creating a high-quality course for seasoned and aspiring family historians has been the need to cater for a broad range of people with differing levels of prior experience. Towards this end, my colleagues in the English discipline took an innovative approach to designing an engaging and inclusive capstone assessment task in Writing Family History, the first of two units that foster students' skill acquisition and development in family history writing. With a view to having students engage with genuine archival learning materials, the teaching team created a mini online archive dubbed the shoebox. In this video, Lisa Fletcher explicates this initiative further and explains how the shoebox contained genealogical records about her Scottish ancestor, Margaret Kennedy, who emigrated to Victoria.

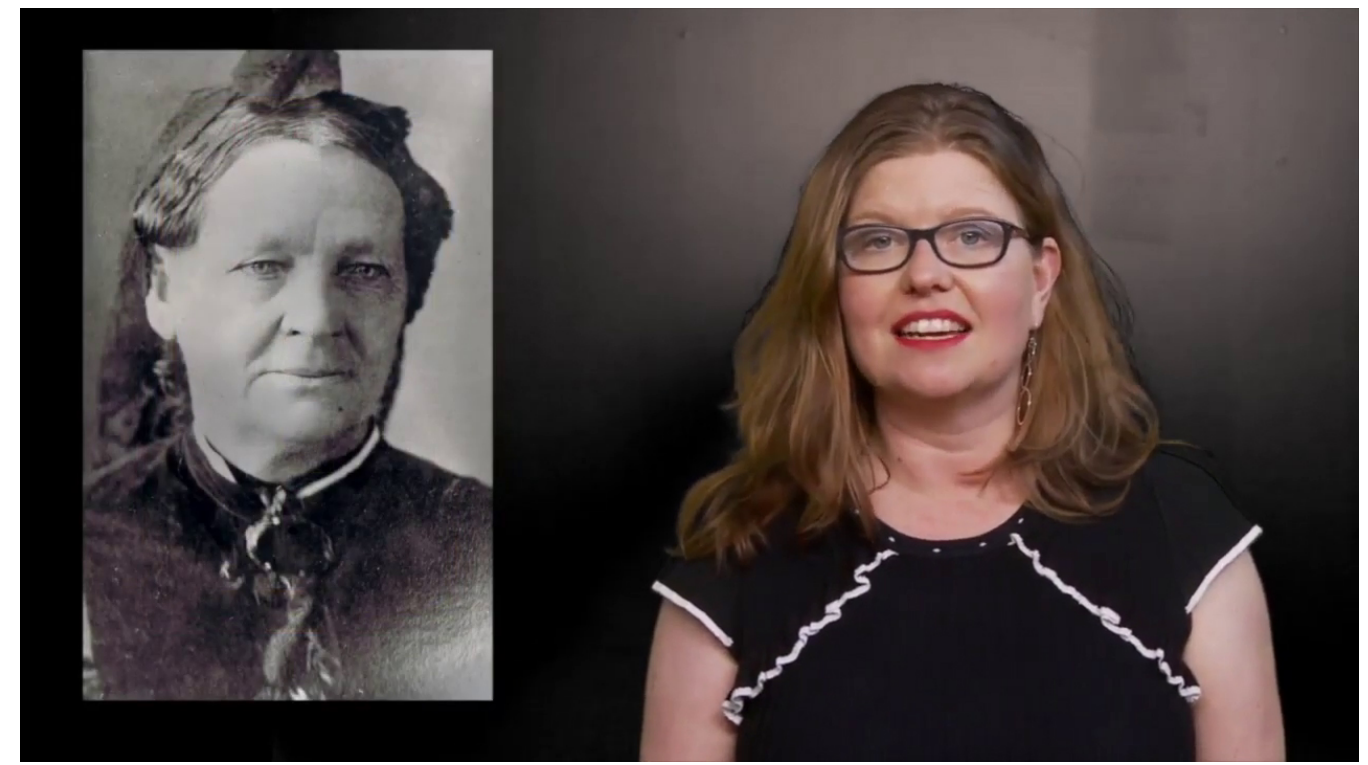

Video 2: Professor Lisa Fletcher from the University of Tasmania explains 'the shoebox'

Particularly over the last decade, online video lectures have been recognized as a "premier" education resource with "well-designed video" acknowledged as leading to "high-level learning." "We use short video lectures typically ranging between five and fifteen minutes' duration to introduce course content to our students, to demonstrate specific skills (such as how best to handle historic papers and photographs), and to situate our ancestors within relevant wider contexts. Some of our videos have been produced in our on-campus studios.

We have also filmed on-site at locations ranging from archives to world heritage-listed convict sites, including Port Arthur.

Located on the Tasman Peninsula, the iconic former penal station has become synonymous with the harshness of the convict regime. Yet when we visited Port Arthur to film on location it was not to emphasize brutality. Our short video lecture featuring Lydia Nicholson forms part of the learning materials near the end of the second of our two convict units, by which time students have identified and worked quite extensively on their convict ancestors' (or borrowed' convicts) lives. Taking a myth-busting approach, Lydia highlights how the vast majority of convicts punished in Australia never spent time at Port Arthur and challenges the ways in which heritage interpretations tend to emphasize punishment. She focuses on the complexity of the convict system and the need for a deeper and broader understanding. 


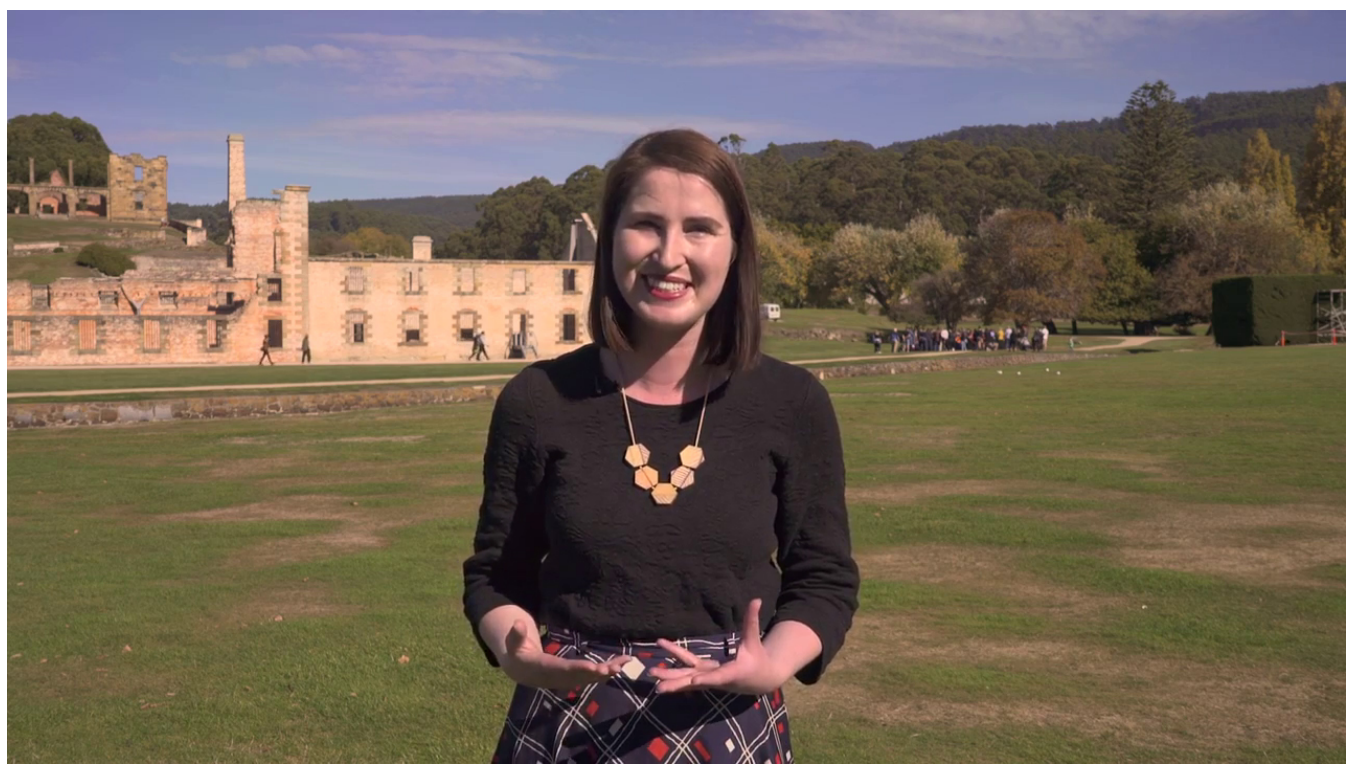

Video 3: University of Tasmania graduate Dr Lydia Nicholson filmed on site at Port Arthur taking a myth-busting approach to convict history

Consistent with our emphasis on authenticity and real-world relevance, it has proven essential to provide our family history students with sometimes quite technical information that extends beyond my and my colleagues' areas of specific expertise. To ensure that students can access the most up-to-date instruction relevant to their practice, we have drawn on experts in our wider community to contribute to the learning experience we provide. For example, people with professional standing in archival storage methods, the uses of DNA for family historians (canvassing both advantages and potential pitfalls), and archival and geographical searches for Chinese Australian ancestry have provided succinct video lectures supplemented by a range of multi-media learning resources.

\section{Immediacy}

Creating an engaging online learning environment is essential to maintaining students' interest in, and promoting their interaction with, their learning materials. The instructor's role in this is vital and relies on an ability "to communicate and engage learners with the subject matter and course colleagues, across distances of time, space and knowledge base.."7 We foster this sense of connection and immediacy for our students through taking a multimedia approach that draws on a tool kit comprising short video lectures, discussion boards, and quizzes. Extending this concept further, we have deliberately cultivated a dynamism online that extends beyond these familiar tools.

In working with any cohort of students, continual assessment through which students can ascertain the extent to which they are learning (formative assessment) through receiving feedback on their work is "important because it has a strong impact on learning." 8 In working with our diverse cohort of family history students, some of whom have university degrees and some of whom are new to tertiary study, formative assessment is all the more important as they build their learning confidence and skills. We have therefore emulated our colleagues who have created an enormously successful dementia care MOOC [massive open online course] in incorporating interactive elements into our students' learning experiences. ${ }^{9}$

Our interactive elements are dynamic and engage students in gamified learning experiences that provide them with instant feedback and multiple opportunities to attempt the tasks until they have achieved an outcome with which they are satisfied. These learning experiences are wide-ranging and are expanding with our incorporation of H5P [HTML5 Package] interactive elements into our learning design. The following example of an interactive element drawn from my Convict Ancestors unit uses an ordering approach. In a week-long module of learning about convict women's and children's experiences, students have an opportunity to click and drag items sewn by convict women until they are ordered correctly from most expensive to least costly. 


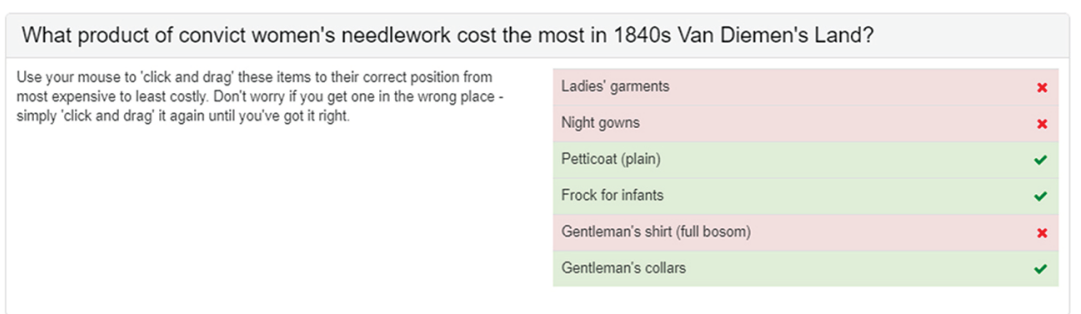

Example of an interactive formative assessment task (or 'e-tivity') from Convict Ancestors

Visual elements including color coding as well as ticks and crosses indicate a student's progress towards ordering these items correctly. Feedback is continual throughout the student's engagement with this interactive element. Continual feedback is built into our course content throughout the delivery of the Diploma of Family History.

\section{Family history as public history}

Centering authenticity in the Diploma of Family History extended to the design and development of capstone assessment tasks. Students engaged with their family histories across a range of media, adopting traditional approaches such as writing biographies to creating innovative responses like producing captioned photo essays. This has led to a range of family history outputs entering the public sphere which include, for example, a selfpublished book of narratives based on their family histories to which thirty-four of our graduates contributed. ${ }^{10}$ This collaborative approach is consistent with David Dean's and Andreas Etges' recent observation that "in practice public history is often, but not always, a collaborative enterprise."11

\section{Conclusion}

The Diploma of Family History emerged on the higher education market in 2016 in response to unprecedented interest in genealogy from an Australian public whose fascination with this pursuit has risen steadily since the 1970s. Family history's popularity may be attributed in no small part to settler Australians' "desire for belonging and political relevance." 12 The urge to delve into a family's past coupled with the rapidly increasing digitization of archival resources that make it possible to do so has meant that an online diploma through which students can acquire access to, and the skills to interpret, utilize, and contextualize, the multitude of digital resources available to them is particularly fit for purpose. Through creating learning experiences imbued with authenticity and delivered with a sense of immediacy, the Diploma of Family History has enjoyed high rates of student engagement and retention. Our students' work has culminated in meaningful summative assessment tasks with real-world relevance, meaning that our graduates have produced portfolios of work that may become legacy pieces for their descendants.

As well as imbuing their own work with academic rigor, some of our graduates have taken on roles in the public sphere such as opening consultancies or taking on consulting roles in libraries, creating a ripple effect as academically-trained family historians impart skills to others who are engaging in researching their own family histories. Yet more have published their family history-derived work with some commercial success. ${ }^{13}$

\section{Notes}

1 Ancestry Library does not include the capacity for students to create online family trees. We introduce students to, and critique, family tree software separately within our foundation unit Introduction to Family History.

2 Tanya Evans, Fractured Families: Life on the Margins in Colonial New South Wales (Sydney: UNSW Press, 2015), 17.

3 Kristyn Harman, "The Transformative Power of Digital Humanities in Teaching Family History Online," Journal of University Learning and Teaching Practice 15, no.3, (2018): Article 7.

4 Stephen J. Brookfield, Becoming a Critically Reflective Teacher (San Francisco: Jossey-Bass, 2017), 2.

5 Caroline M. Crawford, "Instructor Immediacy and Authenticity: Engaging in Cognitive Vulnerability within the Online Instructional Environment" in Steven D'Agustino, ed., Creating Teacher Immediacy in Online Learning Environments (Hershey: IGI Global, 2016 ), 17.

6 Ozlem Ozan and Yasin Ozarlan, "Video Lecture Watching Behaviours of Learners in Online Courses," Educational Media International 53, no. 1 (2016): 27.

7 Caroline M. Crawford, "Instructor Immediacy and Authenticity: Engaging in Cognitive Vulnerability within the Online Instructional Environment" in Steven D’Agustino, ed., Creating Teacher Immediacy in Online Learning Environments (Hershey: IGI Global, 2016$), 16$. 
8 Zwelijongile Gaylard Baleni, “Online Formative Assessment in Higher Education: Its Pros and Cons,” The Electronic Journal of e-Learning 13, no. 4 (2015): 228.

9 Carolyn King, Jo-Anne Kelder, Kathleen Doherty et al, "Wiki Based Collaborative Learning in Interuniversity Scenarios," The Electronic Journal of e-Learning, 12 (2014) 2: 167.

10 Secrets, Twists, Triumphs and Tragedies: An Anthology of Family History Stories (Victoria, 2016).

11 David Dean and Andreas Etges, “What Is (International) Public History?", International Public History 1, no. 1 (2018).

12 Ashely Barnwell, "The Genealogy Craze: Authoring an Authentic Identity Through Family History Research," Life Writing, 10 (2013)

3: 261.

13 See, for example, Diploma of Family History graduate Janeen Ann O'Connell's independently-published trilogy centered on the CullenBartlett Dynasty, No Room for Regret, Love, Lies, and Legacies, and Time Tells All, all of which are available in paperback and Kindle formats via Amazon.com. 